\title{
Investigating Search Behavior and Performance using Personal and Social Context Signals
}

\author{
Dongho Choi \\ Rutgers, The State University of New Jersey \\ 4 Huntington Street \\ New Brunswick, New Jersey 08901 \\ United States \\ dongho.j.choi@rutgers.edu
}

\begin{abstract}
Emerging trends in smart-phones and wearable devices provide us efficient way through we could observe and understand individuals' behavior and allow for the creation of a rich user behavioral profile. Through a user study, personal and contextual signals from participants' everyday lives were collected, while information search behavior was observed in a lab study. Preliminary analysis over data indicates that possibilities of relationship between social/geo-locational interaction between information search performance.
\end{abstract}

Keywords: Search behavior, Social context, Wearable devices

\section{INTRODUCTION}

Emerging technologies and relating devices help people find information and share their knowledge and experience with ease. In addition to the traditional desktop PC environment and smartphones, diverse types of wearable devices are also quickly emerging as information devices/systems through which people search, produce, and share information. While smart-phones make easier ways to quickly seek information and communicate people, wearable devices tend to be focusing on personalized information, such as notification for predefined request and users' biophysical signals. More specifically, various types of sensor on these devices help us understand people's behavior in everyday lives from diverse aspects. Personal and social context information has become much approachable for researchers to study both individual and social behavior in details thanks to the devices and sensors. Interested in exploring signals from various types of sensors and/or devices, a user study was conducted aiming to investigate individual and collaborative search and the factors that relate to them.

\section{BACKGROUND}

An individual, the person who consumes and produces information, has several intrinsic characteristics, such as general behavioral style and personality, as well as preferences toward social relationship and physical activities. Multiple studies have acknowledged the effect of individual personality, demographic descriptors, and personal context in human information behavior (Burdick 1996). However, most studies had to focus on traits that could be easily observed (e.g. gender, ethnicity) or elicited in a short time in laboratory settings. In effect the human personal context was captured by observations made in short, unnatural settings, as recorded or reported by participants or the study conductor and had to contend with multiple challenges, including subjectivity in observation, recall/cognitive/sociocognitive biases, and limited observation opportunities.

Meanwhile, collaboration is considered an activity where individual characteristics and social context work simultaneously in complicated manners. Multiple number of person who has different characteristics and background gather and work together to achieve common goal(s). And the basic assumption and/or expectation of collaboration is that through working together physically or timely, they obtain 
improved outcomes both in quantitatively and qualitatively. Collaboration often involves working with information, such as collaborative search. Collaboratively searching for information can be find in many domains ranging from education (Hyldegå rd 2006) to health-care (Reddy and Jansen 2008). However, we lack of understanding when and how people working together could take the advantage of collaboration and the fruits; what kinds of combination of people benefits collaboration regarding their unique characteristics and contexts.

The emergence of mobile phones and sensors that people wear while undertaking activities of daily living is allowing researchers to create rich personalized models of human behavior in social, spatial, and temporal contexts and connect them to various types of outcomes. Singh et al. (2013) used social behavior that was measured through face-toface interaction, phone call, and SMS use logs, to predict the spending behavior regarding visiting to diverse businesses and overspending. Mobile phone sensors are also used to develop context-aware systems that detects when individual is depressed and he/she requires assistance (Burns et al. 2011), and emotion sensing platform (Rachuri et al. 2010; Yano et al. 2012).

The research questions I have are as follows:

RQ1. To what extent, if any, do behaviors observable via mobile phones relate to information seeking behaviors when people work in individual and/or collaboration?

RQ2. To what extent, if any, do behaviors observable via wearable devices relate to collaborative search behavior?

RQ3. To what extent, if any, are personal signals and social signals different in terms of predicting the search performance?

\section{STUDY}

\subsection{Session Flow}

25 student participated in this study through three batches of session during Spring semester in 2015. The workflow of each session is described in Table 1. The participants were invited to a lab for the introduction during which required apps were installed on their phones and a wearable device was given to each of them. During the field study, participants were not asked to do anything specific except keeping the mobile app installed and wearing the device on their wrist on daily life with regular (automatic, in the background) syncing to the

\subsection{Lab session}

During the lab session, participants were asked to collect relevant information in an exploratory search task on the given topics. The first task (Task 1) was done individually with the topic of "data security," while the second task (Task 2) was done in pair randomly assigned with the topic of "health and wellness".

\subsection{Evaluation}

In order to measure and evaluate the participants' information searching behaviors, and compare the differences between those from individual tasks and collaborative tasks, the study adopted a subsets of evaluation measures suggested in Shah (2014) and Shah et al. (2015). A brief description of the framework is presented in Table 2.

\section{RESULTS AND DISCUSSION}

In this session, results of preliminary correlation analysis between the variables in Table 2 are presented.

\subsection{Individual Search Performance}

Regarding data collected through mobile app, two features show correlation with some of search performance. The number of SMS has positive relationship with Unique Relevant Coverage, while Distinct Location also has positive relationship with Unique Coverage.

The variable of Number of SMS shows the extent to which a person interacts with other individuals through mobile texts. Higher value of this variable means a person frequently sends and receives text messages to and from other people no matter who they are. In the meantime, higher value of Unique Relevant Coverage indicates that a person visited relatively much number of relevant Web pages during the search task. More specifically, when considering the term "unique," the person might have distinct and unique criteria for relevancy. When it comes to the exploratory search, the tendency also infers that an individual who sends/receives relatively higher number of messages per day tends to understand and learn the topic differently from others who does not.

One additional interesting finding is the positive relation between Unique Coverage and Distinct Location. The variable of Distinct Location measures that the total number of distinct locations during a day, captured by different cell tower IDs and/or GPS data. This information does not necessarily 
Table 1: Session Workflow.

\begin{tabular}{|l|l|l|}
\hline Session & Procedure & Description \\
\hline \multirow{4}{*}{ Field Session } & Introduction & $\begin{array}{l}\text { Introduce the study, install required apps and sync the wearable device with a } \\
\text { dedicated app. }\end{array}$ \\
\cline { 2 - 3 } & Field task & $\begin{array}{l}\text { Have participants keep using wearable devices in everyday lives and apps on } \\
\text { the phone, collecting their individual and social context data. }\end{array}$ \\
\cline { 2 - 3 } & Survey & $\begin{array}{l}\text { In the middle of the field session period, ask about their behavioral style, social } \\
\text { capital, and information behavior. }\end{array}$ \\
\hline \multirow{4}{*}{ Lab Session } & Introduction & $\begin{array}{l}\text { Introduce the lab session and information-seeking tasks the participants will } \\
\text { be given. }\end{array}$ \\
\cline { 2 - 3 } & Lab task 1 & Exploratory search task-1. Includes pre-survey and post-survey. \\
\cline { 2 - 3 } & Lab task 2 & Exploratory search task-2. Includes pre-survey and post-survey. \\
\cline { 2 - 3 } & Wrap-up & Wrap-up study and (optional) interview. \\
\hline
\end{tabular}

for activities or commuting. No matter what the purposes of movement, the result indicate that a person who moves more tends to visit Web pages that have not visited by other participants. This brings us an interesting question: "Does geolocational movement affect information exposure to an individual and affect again toward the way of thinking and understanding?"

\subsection{Collaborative Search Performance}

Among the features extracted signals, we found relationship between the dissimilarity in the number of SMS counterparts and the synergy effect. This means that the more participants are different with regard to the social activities that are measured how many people they are keeping to talk with, the less synergy effect they have when working together. Though it is not significant enough, we can see the negative relationship between distinct users for SMS and the ratio of increased Coverage. However, if we selected sample with negative synergy effect, the relationship is much stronger and significant.

An another aspect of SMS usage, the number of SMS that an individual sends and receives per day, shows a relationship with the synergy effect on Relevant Coverage in collaboration $\left(N=12, R^{2}=\right.$ $.344, p=.045)$. This implies that if members in a pair have substantial difference of the extent of using SMS, they tend to have less synergy effect regarding information relevancy.

Seeing the data, even with very limited number of samples, we came up with an interesting question: "Do the large differences in the values of the same feature from the collaborators matter? Or does the minimum value of each feature among the collaborators matter more for group synergy?" This question is inspired by the "Liebig's Law of Minimum (Odum et al. 1971)," which is originally a concept applied to plant or crop growth. It was found that increasing the amount of plentiful nutrients did not cause the increasing plat growth and the yield. Likewise, we suspected even if one participant in a team has incredible potential in terms of productivity and efficiency in the task, the results might not be productive as expected, when the other one cannot support him/her very well.

\subsection{Limitations and Future Work}

There are some limitations on this study. For example, we need to consider the changing techniques and applications people use for chatting, instead of using the conventional simple text messaging. We can easily name a couple of popular chatting applications for smart-phones, which have been replacing texts. The way of using those apps maybe a lot different from the collected data in this study. If we could use a method through which observing interpersonal communication over smartphones, we can conduct much different kinds of experiments and analysis.

Given that only limited number of features were used, we want to see more different aspects of the collected data. We are expecting to see more diverse perspectives toward the data through visualization and deep analysis with additional aspects, such as diversity, loyalty, regularity and so on.

\section{CONCLUSION}

Personal and social contextual signals were collected through smart-phone app and wearable device, while information search behavior was monitored during exploratory search tasks. Preliminary analysis over the extracted features from the raw data indicates several interesting points. Regarding individual task, the number of SMS has positive relationship with Unique Relevant Coverage, and Distinct Location has a positive relationship with Unique Coverage. When it comes to the collaborative task, social interaction (SMS usage) via phones 
Table 2: Variables used in Analysis

\begin{tabular}{|c|c|c|}
\hline Data Source & Features & Description \\
\hline \multirow{4}{*}{ Wearable Device } & Steps & The average number of steps per day of a user during the field study \\
\hline & $\begin{array}{l}\text { Minutes of Seden- } \\
\text { tary }\end{array}$ & $\begin{array}{l}\text { Average minutes of being sedentary per day recognized by the } \\
\text { wearable device }\end{array}$ \\
\hline & $\begin{array}{l}\text { Minutes of Very Ac- } \\
\text { tive }\end{array}$ & $\begin{array}{l}\text { Average minutes of being very active per day recognized by the } \\
\text { wearable device }\end{array}$ \\
\hline & Minutes of Sleep & $\begin{array}{l}\text { Average minutes of being asleep per day recognized by the wearable } \\
\text { device }\end{array}$ \\
\hline \multirow{6}{*}{ Mobile App } & Total Call Time & Average minutes of total call time per day \\
\hline & Number of Calls & Average number of call per day \\
\hline & Number of SMS & Average number of SMS sent/received per day \\
\hline & Distinct User (Call) & Average number of distinct caller/receiver per day \\
\hline & $\begin{array}{l}\text { Distinct } \quad \text { User } \\
\text { (SMS) }\end{array}$ & Average number of distinct sender/receiver for SMS usage per day \\
\hline & Distinct Location & $\begin{array}{l}\text { Average number of distinct location per day, captured by the app using } \\
\text { the number of cell tower around and GPS data }\end{array}$ \\
\hline \multirow{5}{*}{ Searching Task } & Coverage & The total number of distinct Web documents visited by a participant \\
\hline & Unique Coverage & The total number of Web documents visited only by one participant \\
\hline & Relevant Coverage & $\begin{array}{l}\text { The total number of distinct relevant Web documents visited by a } \\
\text { participant }\end{array}$ \\
\hline & $\begin{array}{l}\text { Unique Relevant } \\
\text { Coverage }\end{array}$ & $\begin{array}{l}\text { The total number of distinct relevant Web documents visited only by one } \\
\text { participant }\end{array}$ \\
\hline & Distinct Queries & $\begin{array}{l}\text { The number of distinct queries that were submitted to search engines } \\
\text { by participant }\end{array}$ \\
\hline
\end{tabular}

effect of collaboration. Also, our results implies that the difference between collaborators matter with regard to social interaction, while minimum extent of physical activity relate to the outcomes.

\section{ACKNOWLEDGEMENT}

I thank ELIAS (Evaluating Information Access Systems) ESF Research Networking Programme for the awarded scholarship for participating in ESSIR 2015 and the FDIA Symposium.

\section{REFERENCES}

Burdick, T. A. (1996), 'Success and Diversity in Information Seeking: Gender and the Information Search Styles Model.', School Library Media Quarterly 25(1), 19-26.

Burns, M. N., Begale, M., Duffecy, J., Gergle, D., Karr, C. J., Giangrande, E. and Mohr, D. C. (2011), 'Harnessing context sensing to develop a mobile intervention for depression.', Journal of medical Internet research 13(3), e55.

Hyldegård, J. (2006), 'Collaborative information behaviour-exploring kuhlthaus information search process model in a group-based educational setting', Information Processing \& Management 42(1), 276-298.
Odum, E. P., Odum, H. T. and Andrews, J. (1971), Fundamentals of ecology, Vol. 3, Saunders Philadelphia.

Rachuri, K. K., Musolesi, M., Mascolo, C., Rentfrow, P. J., Longworth, C. and Aucinas, A. (2010), 'EmotionSense', Proceedings of the 12th ACM international conference on Ubiquitous computing - Ubicomp '10 p. 281.

Reddy, M. C. and Jansen, B. J. (2008), 'A model for understanding collaborative information behavior in context: A study of two healthcare teams', Information Processing \& Management 44(1), 256-273.

Shah, C. (2014), 'Evaluating collaborative information seeking - synthesis, suggestions, and structure', Journal of Information Science 40(4), 460475.

Shah, C., Hendahewa, C. and González-ibá nez, R. (2015), 'Two's Company, But Threes No Crowd: Evaluating Exploratory Web Search for Individuals and Teams', Journal of Information Science Sep.

Singh, V., Freeman, L., Lepri, B. and Pentland, A. (2013), 'Classifying spending behavior using socio-mobile data', HUMAN 2(2), pp-99.

Yano, K., Lyubomirsky, S. and Chancellor, J. (2012), 'Sensing happiness', IEEE Spectrum 49(12), 3237. 